\title{
La estela de Antymmer (CG 20098) y el surgimiento de nuevos sectores sociales intermedios en Abidos durante el Reino Medio egipcio
}

\section{Resumen}

Las estelas privadas del Reino Medio procedentes del sitio de Abidos constituyen hoy en día una de las fuentes más importantes de información para poder analizar, comprender y reconstruir la sociedad egipcia. Es por ello que en este trabajo hemos seleccionado una de estas estelas (CG 20098) y la hemos documentado, traducido, analizado y contextualizado. Así, este trabajo se fundamenta en el estudio de la estela CG 20098, la cual pertenece a un sujeto sin títulos ni cargo alguno, llamado Antymmer, que se encuentra representado junto a miembros de su familia y servidores. Su importancia radica en el hecho de que se trata de un sujeto perteneciente a uno de los nuevos sectores sociales intermedios que comienzan a emerger durante el Reino Medio. En este trabajo se analiza, también, el proceso de surgimiento de esos nuevos sectores sociales intermedios en Abidos a partir de la evidencia procedente de dicha estela y del material encontrado en el sitio.

The stela of Antymmer (CG 20098) and the development of new intermediate social classes in Abydos during the Egyptian Middle Kingdom

\begin{abstract}
The Middle Kingdom private stelae, found at Abydos, are some of the most important sources of information to analyze, understand, and reconstruct the Egyptian society. In this article, we are particularly interested in one of these stelae (CG 20098). The stela CG 20098, which belongs to a person called Antymmer, with no job titles or ranks mentioned, represents him and his family together with his servants. Its importance lies in the fact that Antymmer belongs to one of the new intermediate social classes that rose during the Middle Kingdom. Thus, in this paper, we also analyze the development of these new social classes during that period, taking the material evidence found in Abydos into account.
\end{abstract}

\section{Palabras clave}

Egipto

Sociedad

Abidos

Estela

Keywords

Egypt

Society

Abydos

Stela

* Centro de Estudios de Sociedades Precapitalistas, Instituto de Investigaciones en Humanidades y Ciencias Sociales (IdHICS), Facultad de Humanidades y Ciencias de la Educación, Universidad Nacional de La Plata (UNLP) - CONICET. Calle 51 entre 124 y 125 (CP 1925) Ensenada, Buenos Aires, Argentina. E-mail: pablomartinrosell@gmail.com 


\section{Introducción}

El Reino Medio egipcio (2055-1650 a.C.) ha sido considerado como un período de cambios y transformaciones sociales de entre los cuales se destaca la emergencia de nuevos sectores sociales intermedios ligados a una sub elite no dependiente necesariamente del Estado (Parkinson, 1991; Richards, 2005a). Y es precisamente en el sitio de Abidos donde este proceso se puede atestiguar gracias al descubrimiento y estudio de las fuentes arqueológicas allí encontradas, tales como los cenotafios o capillas funerarias y las estelas votivas y funerarias que amplios sectores no ligados a la elite tradicional han legado en dicho lugar en contextos de rituales y celebraciones religiosas vinculados con la divinidad de Osiris. De hecho, las numerosas estelas privadas encontradas en Abidos constituyen hoy en día una de las fuentes más vastas e importantes de información para poder reconstruir ciertas transformaciones socioculturales acaecidas durante el Reino Medio.

Ahora bien, en este contexto nos interesa analizar y estudiar una estela funeraria particular datada del Reino Medio y procedente de dicho sitio. Se trata de la estela CG 20098, perteneciente a un sujeto llamado Antymmer, la que aporta evidencia sobre la capacidad que habrían tenido ciertos sujetos sociales intermedios - no ligados a las elites tradicionales- para poder costearse un monumento funerario y participar de ciertas celebraciones rituales.

La estela CG 20098 es una de las fuentes epigráficas más importantes con la que contamos para reflexionar sobre este proceso de surgimiento de sectores sociales intermedios. $\mathrm{Su}$ importancia radica en el hecho de que se trata de un sujeto no vinculado con la elite tradicional o la burocracia estatal que pudo acceder a un monumento funerario en Abidos y que, además, contiene en su estela representaciones de trabajadores dependientes a su cargo.

Así, este trabajo presenta un estudio y una traducción completa de la estela CG 20098 e intenta, mediante un análisis comparativo con otras fuentes contemporáneas procedentes de Abidos, analizar la emergencia de nuevos sectores sociales intermedios en Egipto.

\section{Estela CG 20098}

La estela CG 20098 (Figura 1), también catalogada e identificada en el Museo Egipcio de El Cairo como JE 20400, fue descubierta por Mariette en 1862 durante los trabajos realizados en el cementerio norte de Abidos y la identificó en su catálogo bajo el número 705 (Lange y Schäfer, 1902a; Mariette, 1880; Simpson, 1974). Hasta el momento, la misma sólo ha sido descripta por Mariette (1880) y reproducida, junto con sus signos jeroglíficos, por Lange y Schäfer (1902a, 1902b), mas no ha sido traducida íntegramente ni se han realizado estudios significativos de la misma. Se trata de una estela funeraria rectangular de $53 \mathrm{~cm}$ de largo por $44 \mathrm{~cm}$ de ancho tallada en bajorrelieve sobre piedra caliza (Lange y Schäfer, 1902a). Actualmente la estela se encuentra en los depósitos del Museo egipcio de El Cairo, conservada en muy buen estado y ha sido seleccionada para su posterior transferencia al Gran Museo egipcio, próximo a inaugurarse en Guiza, donde será catalogada e identificada como GEM 15054.

La misma ha sido datada, gracias a su estilo, como correspondiente al Reino Medio (Bright, 2005; Freed, 1996; Ilin-Tomich, 2017; Mariette, 1880). Más precisamente, es posible datarla a mediados de dicho período, gracias al empleo de varios términos y determinativos plausibles de ser analizados paleográficamente. A saber, un estudio 


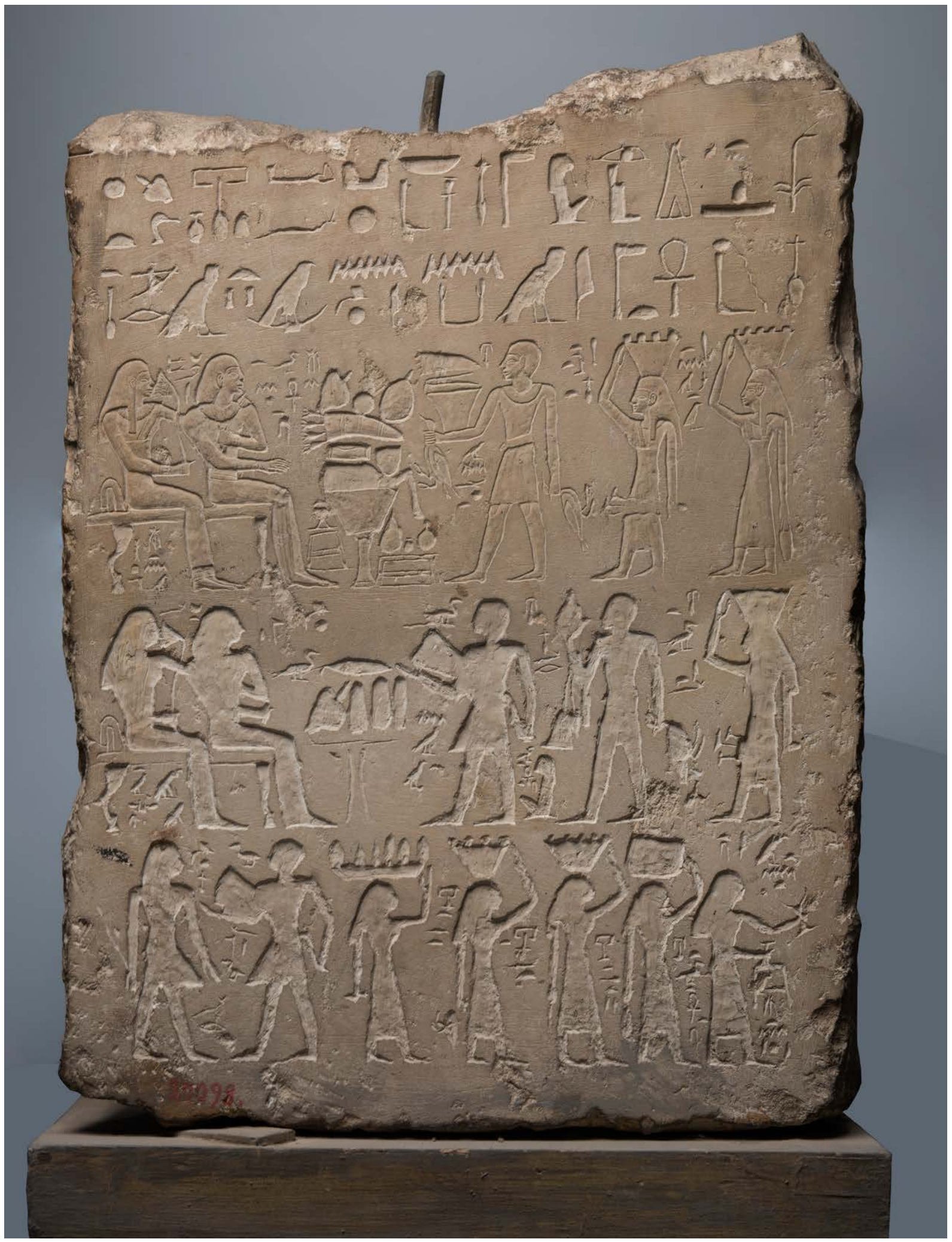

Figura 1. Estela CG 20098. ๑ Museo Egipcio de El Cairo. Foto reproducida con el permiso y la cortesía del Museo Egipcio de El Cairo. 
realizado por Bennett (1941) sobre el desarrollo de la fórmula de ofrendas durante el Reino Medio reveló ciertos patrones de datación en cuanto al uso de algunas frases y el empleo de unos determinativos a la hora de escribir ciertas palabras. En lo que a nuestra estela concierne podemos distinguir los siguientes indicios que nos permitirían datar dicho objeto a mediados de la dinastía XII. Por un lado, la escritura del nombre del dios Osiris con su determinativo divino 5 ? ocurre entre fines de la dinastía XI y la primera mitad de la dinastía XII, dado que a partir del reinado de Sesostris III,

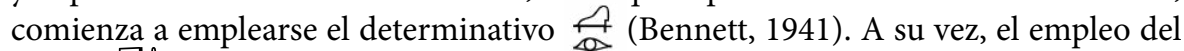
epíteto 7 tr 33 "gran dios" después del nombre del dios Osiris, raramente ocurre en textos previos a la dinastía XII y se comienza a utilizar a partir del reinado del faraón Sesostris I (Bennett, 1941). Asimismo, el empleo en la fórmula de ofrendas de la frase $\triangle \square_{0}$ di.f prt-hrrw, cuyo significado sería "que él pueda dar una ofrenda invocada", es propia de la dinastía XII, puesto que durante la dinastía XI dicha frase se escribía sin sujeto y sin verbo (Bennett, 1941). Por otro lado, el empleo de la frase f. 14 "nht ntr im "en el que vive el dios" o "de lo que vive el dios" luego de la lista de ofrendas es una marca clara de la dinastía XII, dado que dicha frase aparece por primera vez durante el reinado de Sesostris I (Bennett, 1941). Por último, la fórmula de ofrendas concluye señalando cómo dichas ofrendas son para el L del venerado"; esta frase para designar al difunto sólo aparece a partir del reinado de Amenemhat II y perdurará hasta principios del reinado de Amenemhat III (Bennett, 1941). Por ello, a partir de esta evidencia, podríamos postular que la estela CG 20098 habría sido elaborada a mediados de la dinastía XII, entre los reinados de los faraones Amenemhat II y Sesostris III.

Se trata de una de las denominadas estelas votivas que los miembros de las diversas elites egipcias del Reino Medio solían erigir en la ciudad de Abidos, en el marco de las celebraciones por los Misterios de Osiris, con la intención de asegurarse la continua y eterna participación en los ritos después de su propia muerte. La celebración de los Misterios de Osiris en Abidos se fundamentaba en el enterramiento y la regeneración de Osiris, con la consiguiente promesa de entierro y regeneración para los muertos justificados. A raíz de esta celebración que cobró auge durante el Reino Medio egipcio, la ciudad de Abidos se habría convertido en un centro ceremonial (Bleeker, 1967; Chassinat, 1966-1968; Collier y Manley, 2007; Eaton, 2006; Lavier, 1989, 1998; Schäfer, 1904; Smith, 2017).

En su descripción de la estela, Mariette (1880) la divide en tres registros, los cuales conjugan texto con imagen. El primer registro incluye una inscripción de dos líneas horizontales escritas de derecha a izquierda. En dicho texto se explicita la fórmula de ofrendas que el difunto y propietario de la estela, Antymmer, recibe como favor real y divino. Por debajo de dicha inscripción se encuentra integrada una escena en la cual aparecen representados - sentados frente a una mesa de ofrendas- el propietario, Antymmer, junto a su esposa Aai, quienes reciben dichas ofrendas a manos de un servidor y dos criadas. El segundo registro emula la representación del primer registro, aunque en menor calidad y estilo. En esa escena se puede observar a un sujeto llamado Sanetjer, junto con su esposa Mutmesas, sentados frente a una mesa de ofrendas -inferior a la observada en el registro previo y con menor cantidad de productos- recibiendo dichos productos en manos de su hijo Nemtu, quien es secundado por una mujer llamada Satankhets y dos servidores que también portan ofrendas. Por último, en el tercer registro se encuentra representado un sujeto llamado Nefer, quien está de pie recibiendo una ofrenda en manos de su hijo Sanetjer; detrás de él, cinco mujeres que portan ofrendas caminan en dirección contraria al oferente. De estas cinco mujeres, cuatro ostentan el cargo de servidora $w b 3 t$ y quien encabeza a las mismas es identificada bajo el nombre de Nitmutites. Asimismo, dicha mujer aparece identificada como nacida de una tal Ipi, por lo cual, debido a la explicación sobre su filiación, no creemos que se trate de una servidora 
sino de una mujer importante en la vida de Nefer, aunque no tengamos evidencia fehaciente para comprobar esto en la estela.

En cuanto a las relaciones que podrían establecerse entre los diferentes sujetos representados en los registros inferiores con el propietario, Antymmer, es posible plantear la hipótesis de que se trate de una relación parental y que la estela esté representando una filiación genealógica del difunto Antymmer con su familia paterna. A saber en el primer registro, Antymmer es mencionado como hijo de una mujer llamada Satankhets, en tanto que en el segundo registro, aparece representada de forma muy reducida - en relación con los otros sujetos - una mujer llamada Satankhets, detrás de Nemtu, el hijo de Sanetjer. Si bien la estela no menciona filiación alguna entre esta mujer Satankhets con Nemtu o Sanetjer, gracias a la evidencia procedente de la estela CG 20077, perteneciente a un sujeto llamado Nemtu, podemos comprobar que este sujeto tiene a una mujer llamada Satankhets como esposa y a un hijo llamado Antymmer (Lange y Schäfer, 1902a, 1902b). De hecho, la estela CG 20077 menciona que Nemtu es hijo de una mujer llamada Khety y en dicha estela él se encuentra representado junto a una mesa de ofrendas con su esposa Satankhets. De esta manera, el dueño de la estela CG 20077 sería el mismo Nemtu representado en la estela CG 20098 y por ende es el padre de Antymmer. Por ello, la mujer sería la madre del dueño de la estela y los representados en el segundo y tercer registro de la estela serían, por un lado, su padre Nemtu, su abuelo paterno Sanetjer y su bisabuelo paterno Nefer. De esta forma, dado que el objetivo fundamental de las estelas privadas habría sido el de poder perpetuar la identidad y la existencia del difunto para toda la eternidad (Yamamoto, 2015a), Antymmer habría elaborado una estela funeraria en la cual quedase explícito su vínculo genealógico con la familia de su padre y se recordase la memoria y los nombres de sus ancestros. Vale aclarar que el recuerdo de los ancestros y sus nombres era una práctica común entre los antiguos egipcios. De hecho, en varias estelas votivas es frecuente el uso de la expresión $s^{\top} n k h r n . f^{\text {"que }}$ su nombre viva" (Nelson-Hurst, 2010). En suma, siguiendo nuestra hipótesis, lo que Antymmer habría querido destacar mediante la elaboración de dicha estela era su vínculo con la familia de su padre y mostrar la estructura patrilineal que le habría posibilitado llegar a ser quien fue.

Por otra parte, es llamativo en esta estela el hecho que no se especifiquen títulos ni epítetos para poder identificar ni al propietario Antymmer ni a sus antepasados que también reciben ofrendas, Sanetjer y Nefer. De hecho, se trata de una fuente que nos ilustra sobre la posibilidad de un sujeto, Antymmer, que al igual que sus antepasados, no se encontraría vinculado aparentemente con la elite tradicional o la burocracia estatal de poder y que, sin embargo, tuvo el beneficio de poder acceder a colocar un monumento funerario - como lo es dicha estela - en el sitio de Abidos en el marco de las celebraciones rituales en honor a Osiris.

A continuación, ofrecemos la traducción completa de la estela CG 20098:

\section{$1^{\circ}$ Registro:}

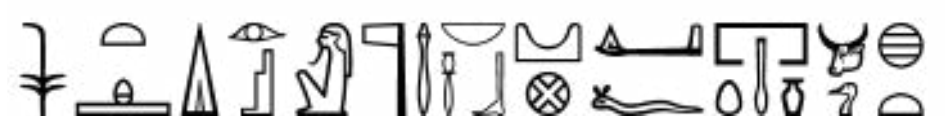

htp di nsw wsir ntrr 93 nb $3 b \underline{d} w$ di. f prt-hrw t ḥnkt $k 3$ 3pd ht

Una ofrenda que da el rey a Osiris, gran dios, señor de Abidos para que él realice una ofrenda invocada de pan, cerveza, piezas de carne de ganado y de ave y cosas 

1. 'nty-m-mr, “Antymmer” (Ranke, 1935,
PN I, p. 69/20). Existen controversias
en torno a la traducción del nombre
del dios. Gardiner (1931, 1947, 2007)
sostuvo que el ideograma G7*
debe leerse 'nty. Sin embargo,
Berlev (1969) ha postulado que el
nombre del dios debe leerse nmty, y
dicha lectura ha sido comúnmente
aceptada por los estudiosos. No
obstante, nuestro trabajo ha optado
por seguir la traducción de dicho
signo según los criterios de Gardiner,
traduciendo al mismo como `nty.

2. De acuerdo a la estela el nombre podría traducirse como Aai o Iaa. Ambos nombres no son referenciados en la obra de Ranke (1935). En este caso hemos optado por traducirlo Aai.

3. Dicho nombre no se encuentra referenciado en el listado elaborado por Ranke (1935).

4. El signo es confuso y podría interpretarse bien como un $D_{31}$ ? $h m k$ 3, o como un $\mathrm{U}_{26}$ i wb3. Mariette (1880) y Lange y Schăfer (1902a) lo han interpretado como U26. Nuestra opinión ha sido considerar a dicho signo como un $U_{26}$, y por ende entender a dicho sujeto como un servidor $w b 3$.

5. El hecho de que un signo del nombre se encuentre erosionado dificulta la posible reconstrucción del nombre. La lectura del signo

$\mathrm{G}_{43}$ resulta ya dudosa para Lange y $y$ chäfer (1902a). La forma del signo resulta muy diferente a signos paralelos cercanos que pueden usarse para comparar. A diferencia de ellos, hemos optado por reconstruir allí el signo $\mathrm{M}_{4} \oint$ el cual nos permite traducir dicho nombre como "Renepetneferet" (Ranke, 1935, PN I, p. 224/11).

6. Ranke (1935, PN I, p. 216/6) lo translitera como ndmwt ("Nedjemut").

7. Signo dudoso. Hemos adoptado la postura de Mariette (1880) y Lange

y Schäfer (1902a) quienes lo han interpretado como un signo $\mathrm{U}_{26} \mathrm{~A}$ transliterándose $w b 3$ : servidor $w b$ ?

Misma postura ha tomado Hannig (2006). También podría tratarse del signo D31 \{?, y referirse a un $h m-k 3$ (servidor del $k a$ ). Hemos optado por identificar a dicho hombre como un servidor $w b 3$ dado que no pareciera estar oficiando el ritual de las ofrendas sino, más bien portando las ofrendas.

8. Ídem nota anterior. Lange y Schäfer (1902a) y Hannig (2006) lo han interpretado como un signo $\mathrm{U}_{2} 6 \mathrm{O}$ Si bien no se descarta que también pueda tratarse de un signo $D_{31}$ (?) y referirse a una servidora del $k a$, en nuestra opinión hemos optado por identificar a dicha mujer como una servidora $w b 3 t$, dado que no pareciera estar oficiando el ritual de ofrendas sino portando bienes para el ritual.

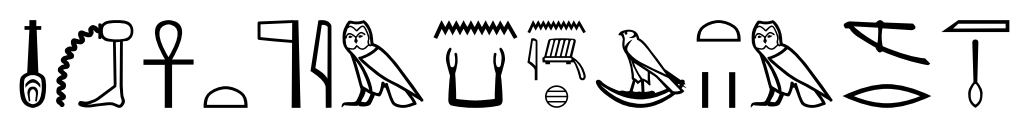

$n f r(w t) w^{\top} b(w t)$ 'nht ntr im $n k 3$ im 3 h `ntymmr m3`-hrw

bellas y puras de lo que vive el dios por el $k a$ del venerado Antymmer ${ }^{1}$, justo de voz.

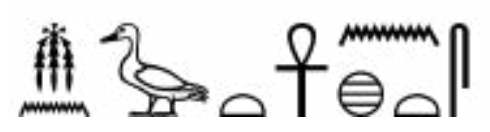

ms $n$ s3t'nhts

Nacido de Satankhets

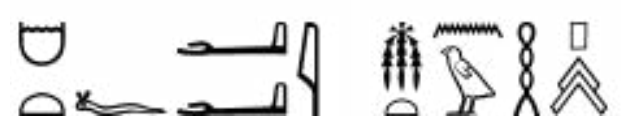

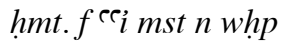

Su esposa Aai, ${ }^{2}$ nacida de Uhep $^{3}$

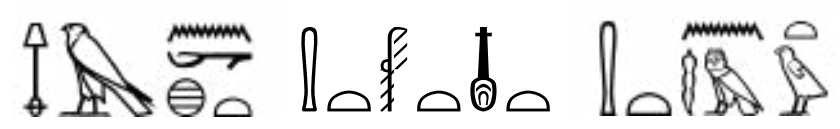

wb $3^{4}$ hrnht hmt rnptnfrt hmt $n d m t w$

Servidor $w b$ 3 Hernekhet, criada Renepetneferet ${ }^{5}(y)$ criada Nedjemtu. $^{6}$

\section{$2^{\circ}$ Registro}
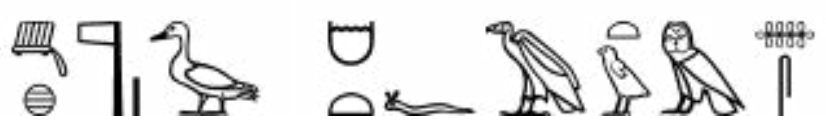

im3h s3ntr hm. fmwtms3s

Venerado Sanetjer, su esposa, Mutmesas.

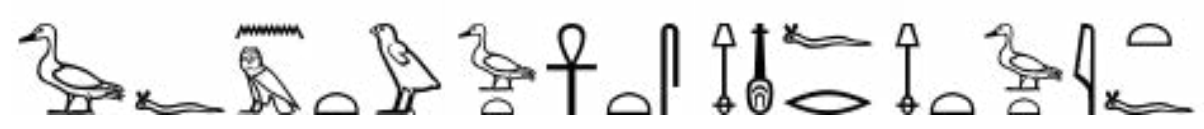

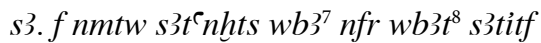

Su hijo Nemtu, Satankhets, servidor $w b 3$ Nefer (y) servidora $w b 3 t$ Satitef.

\section{$3^{\circ}$ Registro}

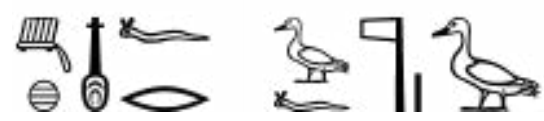




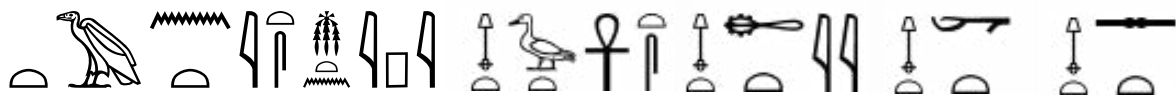

mwt nt its mst $n$ ipi wb3t s3t'nhts wb3t hty wb3t ht wb3t st

Nitmutites, ${ }^{9}$ nacida de Ipi, servidora $w b 3 t$ Satankhtets, servidora $w b 3 t$ Khety, servidora $w b 3 t$ Khet (y) servidora $w b 3 t \operatorname{Set}^{10}$.

\section{Evidencia del surgimiento de nuevos sectores sociales intermedios}

Decíamos, previamente, que una de las características más relevantes de la estela CG 20098 era el hecho de que ni el propietario de ésta ni sus antepasados ostentan o reciben títulos o cargos tradicionales. Así, pareciera como si Antymmer, junto con su padre, su abuelo y su bisabuelo, provinieran de un entorno social no relacionado a las tradicionales estructuras egipcias ligadas a la elite palatina o burocrática. Al respecto, cabe pensar en la posibilidad de que Antymmer haya decidido explícitamente resaltar su origen social e identificar y representar a sus antepasados en su monumento como una forma de manifestar su ascenso social desde sectores no tradicionales. De ahí la importancia que tendría esta estela a la hora de pensar el surgimiento de sectores sociales intermedios durante el Reino Medio que habrían podido, en un proceso de emulación de elite, costearse monumentos funerarios y participar de ciertas tradiciones y espacios rituales privativos de las elites tradicionales y dependientes del Estado.

Ahora bien, por sectores sociales intermedios nos referimos a todos aquellos sujetos que no poseen u ostentan títulos ni cargos administrativos, por lo cual parecieran no ser parte ni del grupo selecto de nobles ligados con la familia real o las elites provinciales, ni de la estructura administrativa y burocrática egipcia. Al respecto, se ha argumentado que estos sujetos podrían ser personas libres, agricultores propietarios de pequeñas propiedades, artesanos y mercaderes que se habrían enriquecido, durante y luego del Primer Período Intermedio (2181-2055 a.C.), hasta el punto de transformase en un sector social intermedio (Erman, 1894; Hayes, 1971). De este modo, si bien estos nuevos grupos sociales no habrían gozado del prestigio social de pertenecer a la elite cortesana y dependiente del Estado, sí habrían podido emularla en sus lógicas socioculturales.

La evidencia material que avalaría el surgimiento de estos nuevos sectores sociales intermedios - del cual Antymmer y su familia son un fiel exponente- procede fundamentalmente del sitio de Abidos. Al respecto, durante el Reino Medio, dicho sitio se habría convertido en un centro ceremonial funerario y religioso asociado con el dios Osiris, hacia el cual los miembros de las diversas elites egipcias solían peregrinar para dedicar y erigir estelas, levantar capillas y dedicar ofrendas con la intención de asegurarse la continua y eterna participación en los ritos después de su propia muerte (Bard, 2008; Collier y Manley, 2007; Lichtheim, 1988; Snape, 2011; Yamamoto, 2015a). Si bien es cierto que a la gran mayoría de estas personas no se les permitía el acceso a las áreas sagradas del recinto del templo de Osiris que allí se encontraba, sí se les permitía atestiguar la performance de los rituales y procesiones, ser enterrados en los cementerios norte y medio y elaborar capillas funerarias sobre la zona votiva para poder depositar sus estelas (Yamamoto, 2015b).

Estas estelas privadas, que muchos peregrinos o miembros de las elites solían dejar en Abidos, eran colocadas en el interior de cenotafios o capillas sagradas, denominadas 
capillas $m^{\top} h{ }^{\top} t$, (Kemp, 1975; O'Connor, 2009; Selim, 2000; Snape, 2011). Las mismas se concentraban en torno a la zona votiva conocida como la "terraza del gran dios", en referencia a las zonas elevadas que unían el camino entre el templo de Osiris y la zona de Umm el-Qaab, por donde pasaba la procesión anual de Osiris (Selim, 2000; Yamamoto, 2015b). Estas capillas o cenotafios, hechos de ladrillos de barro y piedra, eran construidas para resguardar y contener en su interior a las estelas privadas que los miembros de las elites egipcias y los peregrinos ofrecían al acudir a las celebraciones rituales anuales en honor a Osiris en Abidos (Snape, 2011). Las capillas más simples eran abovedadas y hechas de ladrillos, adobe y yeso, mientras que las realizadas por miembros de mayor nivel socioeconómico eran capillas más grandes, amplias, con cámaras interiores y hasta patios, emulando verdaderas tumbas (Yamamoto, 2015b). La mayoría de las capillas encontradas en Abidos pertenecerían al primer grupo de capillas pequeñas y simples, por lo cual se infiere que pudieron haber sido erigidas por miembros no tan acaudalados, pertenecientes a una incipiente sub elite o a sectores sociales intermedios, mientras que también se han encontrado diminutas capillas - construidas con materiales reutilizados cercanos a los muros de los grandes monumentos- las que habrían sido erigidas por los peregrinos más humildes que también buscaban expresar su devoción y ser parte de las celebraciones rituales (Yamamoto, 2015b).

En este sentido, Parkinson (1991) ha planteado que durante la dinastía XII se habría producido un incremento de los números de las capillas funerarias privadas en la necrópolis de Abidos, lo cual se ligaba a un cambio en la estructura social egipcia que habría derivado del surgimiento de una sub elite capaz de afrontar los gastos de sus monumentos y ajuares funerarios. En coincidencia con esto, Richards (2005a) también ha argumentado a favor de la existencia de una clase media egipcia a partir del estudio de los hallazgos de Abidos. Por su parte, Bourriau (1991), ha refutado la idea de la emergencia de una clase media o intermedia egipcia al señalar que es muy difícil distinguir el crecimiento del poder político individual a expensas del faraón en la práctica y evidencia funeraria. Sin embargo, de acuerdo con Richards (2005a), las evidencias más fehacientes que sustentarían la emergencia de nuevos sectores sociales (clases medias o sub elites) proceden del gran número de estelas votivas y funerarias pertenecientes a individuos sin cargos, títulos o rangos oficiales que fueron halladas en las cercanías del complejo del templo de Osiris en la zona del cementerio norte de Abidos. En otras palabras, estas estelas privadas encontradas en Abidos atestiguarían un proceso de transformación social durante el Reino Medio egipcio ligado con el surgimiento de nuevos sectores sociales (Richards, 2005a). Al respecto, se ha asociado esta transformación social con el denominado proceso de democratización de la vida del Más Allá. Sin embargo, estudios recientes han comenzado a cuestionar dicha noción de una democratización de la vida del Más Allá durante el Primer Período Intermedio, con la crisis de la monarquía. Así, en coincidencia con los autores que cuestionan esta noción, compartimos la idea de que tal democratización no habría existido puesto que ya durante el Reino Antiguo (2686 - 2188 a.C.) hay evidencia de sujetos no vinculados con la realeza que pueden acceder a tumbas y fórmulas funerarias porque tanto la clase gobernante como el resto de la sociedad egipcia compartían los mismos deseos y las mismas aspiraciones de una vida en el Más Allá (Cervelló Autuori, 2015-2016; Hays, 2011; Smith, 2009, 2017). Por otra parte, hay autores como Grajetzki (2006) que sostienen que la ausencia de cargos, o títulos en contextos funerarios, se debe a otras razones distintas a un cambio social específico de este período.

La mayoría de las estelas privadas pertenecientes a miembros de esta nueva sub elite o sectores sociales intermedios fueron encontradas en el cementerio norte, lindante con la denominada zona votiva de Abidos (Richards, 2005b). Este es uno de los cementerios provinciales más grandes conocidos del Reino Medio egipcio y el que provee la mayor información sobre las prácticas mortuorias de individuos no ligados con las elites tradicionales (Richards, 2005a, 2005b). Este cementerio habría sido el principal sitio 
de enterramiento y construcción de cenotafios para los miembros de la sociedad que no pertenecían a la realeza tales como las elites locales, así como también para los miembros de la nueva sub elite o sectores sociales intermedios (Richards, 2005b).

De este modo, la evidencia procedente de la estela CG 20098, hallada en dicho cementerio norte, sería un claro ejemplo de este proceso de surgimiento de nuevos sectores sociales intermedios en Abidos. A lo largo de los tres registros de la estela no se menciona título o cargo alguno para los personajes allí representados como los propietarios o ancestros del propietario del monumento. De hecho, Antymmer, junto con su esposa, es retratado acompañado sólo con su nombre y lo mismo sucede con el padre y los abuelos de Antymmer. Esta situación nos permite pensar que se trataba de sujetos procedentes de un contexto social alejado de la tradicional elite palatina o provincial egipcia, pero con un cierto poder económico capaz de lograr la elaboración de estelas funerarias. Sin ir más lejos, tanto Antymmer como su padre Nemtu habrían podido costearse cada uno su respectiva estela en el sitio de Abidos. Y, así como sucede en la estela CG 20098, la estela de su padre, Nemtu (CG 20077), tampoco presenta títulos o cargos burocráticos para las personas allí retratadas. Por ende, los únicos vínculos que ligarían a los sujetos representados en dichas estelas serían más bien los familiares.

Sin embargo, la estela CG 20098 de Antymmer presenta un detalle significativo como es el hecho de que en ella aparezcan representados, junto al propietario, tres trabajadores dependientes identificados con sus nombres propios y sus respectivos cargos. Por un lado, en el primer registro se puede apreciar como un servidor $w b$ 3, seguido por dos trabajadoras dependientes, se encuentra oficializando el ritual de ofrendas para Antymmer y su esposa. Si bien en los registros inferiores el rol del oferente ritual es ocupado por un hijo (Nemtu con su padre Sanetjer o Sanetjer con su padre Nefer), cabe la posibilidad de pensar que quizás Antymmer y su esposa no tuvieran hijos y, por lo tanto, dicha escena fuese oficializada por uno de sus servidores de máxima confianza. De este modo, el ritual de ofrendas es encabezado por un servidor llamado Hernekhet, identificado como un trabajador $w b 3$, es decir un servidor o asistente de confianza. Por otra parte, seguido a dicho sujeto, se encuentran dos criadas personales de la pareja llamadas Renepetneferet y Nedjemtu. Lo notable de esta estela es el hecho de que nos encontramos con un sujeto, Antymmer, perteneciente a un sector social intermedio que no sólo puede costearse un monumento funerario en Abidos, sino que también posee a su cargo a tres trabajadores dependientes. Asimismo, tanto su abuelo Sanetjer como su bisabuelo Nefer, también aparecen en dicha estela ostentando sus respectivos servidores $w b 3$ y $w b 3 t$, los cuales también son representados e identificados mediante sus propios nombres. En este sentido, dado que las escenas funerarias de tumbas y estelas buscaban representar y perpetuar una imagen ideal de la vida del difunto, no es extraño pensar que las representaciones iconográficas de estos trabajadores hayan intentado cumplir una doble función en esta estela: por un lado elevar y jerarquizar el estatus social de Antymmer y sus antepasados al representarlos como miembros de un sector social capaz de ostentar ciertos servidores y, por el otro, perpetuar en la otra vida las relaciones con sus trabajadores dependientes y personales. A su vez, como señala Yamamoto (2015a), la inclusión de estos trabajadores en representaciones iconográficas -además de garantizar su servicio a sus señores- habría permitido que perduraran el recuerdo, la memoria y la identidad de estos grupos sociales que se encontraban incapaces de costearse capillas o estelas funerarias.

Por otra parte, no debemos olvidar que toda representación social siempre es representación de algo y de alguien y que la misma suele estar definida por su relación con otro. De esta manera, la representación social condensaría en una o varias imágenes, historias, relaciones sociales y prejuicios que debemos desenredar y desentrañar para poder transformar dichas representaciones sociales en una herramienta o vehículo para poder interpretar y pensar una realidad social dada. 
En este sentido, las representaciones contenidas en esta estela, como sucede también con las decoraciones de tumbas de miembros de las elites, expresan una jerarquía social (Baines, 2013). Por consiguiente, lo que emerge sería una reafirmación simbólica de la separación social entre los grupos privilegiados, como Antymmer y su esposa, que esperan sentados, bien vestidos y ornamentados la llegada de ofrendas que le traen los grupos no privilegiados que se encontraban bajo su mando (Richards, 2005a).

Así, la evidencia procedente del estudio de la estela CG 20098 nos ilustra sobre la capacidad socioeconómica que la emergente clase social intermedia egipcia habría podido desarrollar durante el Reino Medio. Por otra parte, esta estela demostraría que la ostentación de trabajadores dependientes no era algo privativo de las elites tradicionales: en este caso, tanto Antymmer como sus antepasados se vanagloriaban de ello.

Ahora bien, la evidencia procedente de la estela CG 20098 no es la única que nos ilustra sobre la emergencia de sectores sociales intermedios durante el Reino Medio. Además de la estela CG 20077 perteneciente a su padre, Nemtu, existe una vasta cantidad de estelas procedentes del sitio de Abidos que también confirmarían la capacidad socioeconómica de ciertos sujetos no ligados con las elites tradicionales y que son capaces de costearse un monumento funerario en Abidos. Un ejemplo de esto es la estela de un sujeto llamado Intef, en la cual no se detalla título ni rango alguno, sino que sólo se menciona a algunos miembros de su familia. La misma se encuentra hoy en día en el Museo de Arqueología y Antropología de la Universidad de Pensilvania bajo el rótulo 69-29-122 (Richards, 2005a). Otra de las estelas que nos informa de este proceso de transformación social es la estela de Dedu, encontrada en el interior de una capilla en el cementerio norte de Abidos (Capilla 2 E 725/N 940, Richards, 2005a). En dicha estela se mencionan las ofrendas realizadas en honor a los dioses y la figura del faraón Sesostris I que le concede ofrendas a un sujeto llamado Dedu, que tampoco contiene títulos burocráticos o cargo alguno y que sólo es mencionado bajo el epíteto de "uno que alaba a su señor" (Richards, 2005a). Por último, procedentes del cementerio norte, se destacan una serie de estelas de personas que no poseen títulos burocráticos ni cargos reales, pertenecientes a esta nueva sub elite o sectores sociales intermedios. Nos referimos a la estela CG 20060 de Hetep, a la estela CG 20300 de Khnumhotep, a la estela CG 20589 de Sehetepib y a la estela CG 20139 de Sadedit (Lange y Schäfer, 1902a, 1902b, 1908).

Con todo, lo cierto es que durante este período se produjo un crecimiento notable de monumentos y estelas funerarias a manos de sujetos privados como nunca había sucedido. Esta situación se verá reflejada en el aumento de los talleres de artesanos encargados de fabricar estelas mortuorias para la industria funeraria de Abidos (Freed, 1996; Jay, 2010). Sin embargo, el aumento de la demanda de estelas funerarias en Abidos por parte de estos nuevos sectores sociales intermedios que buscaban emular las prácticas culturales de la elite palatina habría llevado a un deterioro en la calidad de las estelas. Así, mientras que la monarquía y los miembros de la elite cortesana habrían seguido contando con los trabajos de selectos grupos de artistas y artesanos para la realización de sus monumentos, los miembros de estos nuevos grupos sociales habrían contado con artesanos de menor jerarquía a juzgar por la calidad inferior de sus obras (Yamamoto, 2015a). Como consecuencia, el ascenso de nuevos sectores sociales a las prácticas culturales y funerarias de las elites tradicionales habría generado una masificación de la industria de estelas funerarias para Abidos y, con ello, un detrimento de la calidad artesanal. Pero, si bien la calidad del monumento distinguiría a dichos miembros de las elites tradicionales y palatina, el hecho de poder costearse una estela - aunque de baja calidad-cerca del recinto del templo de Osiris y de representarse emulando prácticas tradicionales de las elites egipcias, hará que estos miembros logren elevar su estatus social y diferenciarse del resto la sociedad egipcia que no podía acceder a tales bienes. 
Podría afirmarse que estos nuevos sectores sociales intermedios surgidos durante el Reino Medio egipcio habrían intentado, mediante su representación en estelas funerarias, emular las lógicas de reproducción social de las elites tradicionales con la intención de legitimarse socialmente. En este sentido, dado que el poder, el prestigio y la legitimidad de las elites antiguas se habría basado en la apropiación de un orden fundado en la inequidad y la desigualdad social (Baines y Yoffee, 1988), el hecho de ser una minoría que puede acceder a la posesión de estelas funerarias - en las cuales suelen ser representados distinguidamente- los diferenciaría y alejaría del resto de la sociedad.

\section{Consideraciones finales}

En este trabajo hemos realizado un estudio y una traducción completa con comentarios de la estela CG 20098, la cual pertenece a un sujeto sin títulos ni cargos llamado Antymmer, que se encuentra representado junto a miembros de su familia y sirvientes.

En la primera parte nos hemos abocado a la documentación y descripción de la estela junto con sus características físicas y peculiares. Asimismo, hemos intentado contextualizar a la misma y proponer una posible fecha de datación entre los reinados de Amenemhat II y Sesostris III a partir de ciertos criterios filológicos y paleográficos. A su vez, hemos logrado identificar los lazos de parentesco presentes en dicha estela a partir del hallazgo de la estela CG 20077 perteneciente a su padre, Nemtu, lo cual nos permitió reconstruir las filiaciones de parentesco presentes en la estela CG 20098.

Por otra parte, a partir de la inexistencia de cargos, títulos o rangos que identifiquen a Antymmer como un miembro de la elite tradicional o cortesana egipcia, hemos analizado cómo dicha estela sería una de las tantas evidencias materiales que confirmarían la emergencia de nuevos sectores sociales intermedios durante el Reino Medio. En tal sentido, hemos observado cómo - en el marco del desarrollo del culto a Osiris en Abidos- se habría producido un incremento en la construcción de capillas funerarias privadas, así como de cenotafios y estelas que nos informan de la existencia de sectores sociales no vinculados con la elite tradicional y dan cuenta de un proceso de trasformación social ligado con el surgimiento de nuevas elites o sectores sociales intermedios capaces de costearse monumentos funerarios a imagen y semejanza de la elite tradicional egipcia. Desde esa perspectiva, hemos analizado cómo la estela CG 20098 se inscribe dentro de este proceso de transformación social ligado al surgimiento de sectores sociales intermedios que comienzan a poder costearse monumentos funerarios en el sitio de Abidos en un claro proceso de emulación de elite.

En suma, en este trabajo hemos ofrecido el primer estudio con traducción completa de la estela CG 20098 y, a partir de ella y de varias estelas funerarias, hemos intentado aproximarnos al análisis del surgimiento de nuevos sectores sociales intermedios durante el Reino Medio en el sitio de Abidos.

\section{Agradecimientos}

El presente artículo es resultado de una estancia de investigación realizada en el Museo Egipcio de El Cairo (Egipto) en febrero de 2018. Dicha estancia fue posible gracias al subsidio para viajes y/o estadías otorgado por la Universidad Nacional de La Plata ( ${ }^{\circ}$ de resolución: 592/17). Asimismo, este artículo ha sido posible gracias a mi participación dentro del Proyecto de Investigación y Desarrollo: H807 "Estudios sobre las elites en Abidos a partir de las estelas del Museo de El Cairo" (2017-2018), radicado en el Centro de Estudios de Sociedades Precapitalistas del Instituto de Investigaciones 
y Ciencias Humanas de la Facultad de Humanidades y Ciencias de la Educación de la Universidad Nacional de La Plata, y dirigido por la Dra. Andrea P. Zingarelli.

Quisiera realizar un agradecimiento al Museo Egipcio de El Cairo por otorgarme los permisos para estudiar y reproducir las imágenes de la estela CG 20098. A su vez, quisiera agradecer especialmente a la jefa del Departamento de Documentación y de Gestión del Registro de Colecciones, Marwa Bdr El Din, y a la curadora del Museo egipcio de El Cairo y miembro del Departamento de Documentación y de Gestión del Registro de Colecciones, Norhan Hassan Salem, por su ayuda y cordial gentileza durante mi estadía en el Museo egipcio de El Cairo. Gracias a su colaboración, se me permitió tener acceso a la base de datos del museo y obtener los permisos para el estudio y reproducción fotográfica de la estela CG 20098.

Quisiera agradecer a los evaluadores anónimos de este artículo por sus valiosos comentarios, sus sugerencias, críticas e ideas que contribuyeron a mejorarlo sustancialmente. También quiero brindar un agradecimiento especial a la Dra. Andrea P. Zingarelli por su lectura previa del manuscrito y sus comentarios, así como por su inagotable generosidad y ayuda.

Por último, quisiera agradecer a la Dra. Liliana Manzi y la Dra. Judith Charlin por haberme invitado a formar parte de este dossier. 


\section{Referencias citadas}

》Baines, J. (2013). High Culture and Experience in Ancient Egypt. Sheffield: Equinox.

"Baines, J. y Yoffee, N. (1988). Order, Legitimacy, and Wealth in Ancient Egypt and Mesopotamia. En G. Feinman y J. Marcus (Eds.), Archaic States (pp. 199-260). Santa Fe: School of American Research Press.

» Bard, K. (2008). An Introduction to the Archaeology of Ancient Egypt. Oxford: Blackwell Publishing.

" Bennett, C. J. (1941). Growth of the Htp-Di-nsw Formula in the Middle Kingdom. Journal of Egyptian Archaeology, 27, 77-82.

» Berlev, О. (1969). Сокол, плывущийвладье, иероглиф и бог. ВДи, 1, 3-3о.

» Bleeker, C. J. (1967). Egyptian Festivals. Enactment of Religious Renewal. Leiden: Brill.

" Bourriau, J. (1991). Patterns of change in burial customs during the Middle Kingdom. En S. Quirke (Ed.), Middle Kingdom Studies (pp. 3-20). Kent: Whitestable.

" Bright, D. (2005). Dating Funerary Stelae of the Twelfth Dynasty: A Statistical Study. Sídney: Macquarie University.

"Cervelló Autuori, J. (2015-2016). A vueltas con la teoría de la "democratización" del más allá tras el Reino Antiguo: algunas ideas. Isimu, 18-19, 91-102.

"Chassinat, E., (1966-1968). Le mystère d'Osiris au mois de Khoiak I-II. El Cairo: L'Institut Français d'Archéologie Orientale.

"Collier, M. y Manley, B. (2007). Introducción a los jeroglíficos egipcios. Madrid: Alianza.

»Eaton, K. (2006). The Festivals of Osiris and Sokar in the Month of Khoiak. Studien zur Altägyptischen Kultur, 35, 75-101.

"Erman, A. (1894). Life in Ancient Egypt. Londres: Macmillan and Co.

» Freed, R. (1996). Stela Workshops of Early Dynasty 12. En P. Der Manuelian (Ed.), Studies in Honor of William Kelly Simpson (pp. 297-336). Boston: Museum of Fine Arts.

》Gardiner, A. (1931). Additions to the Hieroglyphic Fount. Journal of Egyptian Archaeology, $17(3 / 4), 245-247$.

" Gardiner, A. (1947). Ancient Egyptian Onomastica. Vol. II. Londres: Oxford University Press.

» Gardiner, A. (2007 [1927]). Egyptian Grammar. Oxford: Griffith Institute.

"Grajetzki, W. (2006). The Middle Kingdom of Ancient Egypt. History, Archaeology and Society. Londres: Duckworth.

" Hayes, W. (1971). The Middle Kingdom in Egypt. En I. E. S. Edwards, C. J. Gadd y G. L. Hammond (Eds.), Cambridge Ancient History. Vol. I. Part 2: Early History of Middle East (pp. 464-531). Cambridge: Cambridge University Press.

" Hannig, R. (2006). Ägyptisches Worterbuch Il: Mittleres Reich und Zweite Zwischenzeit. Teil 1 y 2. Mainz am Rhein: Philipp von Zabern.

" Hays, H. (2011). The death of the Democratisation of the Afterlife. En N. Strudwick y H. Strudwick. (Eds.), Old Kingdom. New Perspectives. Egyptian Art and Archaeology 2750-2150 BC. (pp. 115-130). Oxford: Oxbow Books. 
" Ilin-Tomich, A. (2017). From Workshop to Sanctuary. The Production of Late Middle Kingdom Memorial Stelae. Londres: Golden House Publications.

" Jay, J. E. (2010). Naga-ed-Deir to Thebes to Abydos: The Rise and Spread of the "Couple Standing before Offerings" Pose on FIP and MK Offering Stelae. Journal of the American Research Center in Egypt, 46, 63-80.

» Kemp, B. (1975). Abydos. En W. Helcky E. Otto (Eds.), Lexicon der Ägyptologie. Band I (pp. 28-42). Wiesbaden: Harrassowitz.

» Lange, H. y Schäfer, H. (1902a). Catalogue général des Antiquités égyptiennes du Musée du Caire, no 20001-20399. Grab-und Denksteine des Mittleren Reichs, I. Berlín: Reichsdruckerei.

" Lange, H. y Schäfer, H. (1902b). Catalogue général des Antiquités égyptiennes du Musée du Caire, no 20001-20780. Grab-und Denksteine des Mittleren Reichs, IV. Berlín: Reichsdruckerei.

»Lange, H. y Schäfer, H. (1908). Catalogue général des Antiquités égyptiennes du Musée du Caire, nํ20400-20780. Grab-und Denksteine des Mittleren Reichs, II. Berlín: Reichsdruckerei.

» Lavier, M. C. (1989). Les mystères d'Osiris à Abydos d'après les stèles du moyen empire et du nouvel empire". En S. Schoske (Ed.), Akten des vierten Internationalen Ägyptologen Kongresses München 1985. Band 3. Linguistik - Philologie - Religion (pp. 289-295). Hamburgo: Helmut Buske Verlag.

» Lavier, M. C. (1998). Les fêtes d'Osiris à Abydos au Moyen Empire et au Nouvel Empire, Égypte, Afrique et Orient, 10, 27-33.

» Lichtheim, M. (1988). Ancient Egyptian Autobiographies Chiefly of the Middle Kingdom. A Study and an Anthology. Freiburg: Universitätsverlag Freiburg.

" Mariette, A. (1880). Catalogue général des monuments d'Abydos découverts pendant les fouilles de cette ville. París: L'imprimerie nationale.

"Nelson-Hurst, M. (2010). '...who causes his name to live'. The vivification formula through the Second Intermediate Period. En Z. Hawass y J. Wegner (Eds.), Millions of Jubilees. Studies in honor of David P. Silverman (Volumen 2, pp. 13-31). El Cairo: Conseil Suprême des Antiquités de L'Égyptie.

" O'Connor, D. (2009). Abydos: Egypt's First Pharaohs and the Cult of Osiris, Londres: Thames and Hudson.

》 Parkinson, R. (1991). Voices from Ancient Egypt: An Anthology of Middle Kingdom Writings. Londres: British Museum Press.

» Ranke, H. (1935). Die ägyptischen Personennamen, volumen 1: Verzeichnis der Namen. Glückstadt: J. J. Augustin.

" Richards, J. (2005a). Society and Death in Ancient Egypt: Mortuary Landscapes of the Middle Kingdom, Cambridge: Cambridge University Press.

» Richards, J. (2005b). Abydos, Middle Kingdom Cemetery. En K. Bard (Ed.), Encyclopedia of the Archaeology of Ancient Egypt (pp. 104-106). Londres: Routledge.

» Schäfer, H. (1904). Die Mysterien des Osiris in Abydos unter König Sesostris III. Nach dem Denkstein des oberschatzmeisters I-cher-nofret in Berliner Museum. Leipzig: Hinrichs.

» Selim, H. (2000). The Stela of $h r-w d \underline{d} 3 w$ in the Cairo Museum (JE 41332). Studien zur Altägyptischen Kultur, 28, 243-256.

"Simpson, W. K. (1974). The Terrace of the Great God at Abydos: The Offering Chapels of Dynasties 12 and 13. New Heaven: Peabody Museum of Natural History of Yale University. 
"Smith, M. (2009). Democratization of the Afterlife. En J. Dieleman y W. Wendrich (Eds.), UCLA Encyclopedia of Egyptology. Los Ángeles. s/r (http://digital2.library.ucla.edu/ viewltem.do?ark=21198/zzoo1nf62b). [consultado: 1/02/2019].

»Smith, M. (2017). Following Osiris. Perspectives on the Osirian Afterlife from Four Millennia. Oxford: Oxford University Press.

» Snape, S. (2011). Ancient Egyptian Tombs: The Culture of Life and Death. Malden: WileyBlackwell.

"Yamamoto, K. (2015a). The Art of the Stela. An Appeal to the Living. En A. Oppenheim, D. Arnold y K. Yamamoto (Eds.), Ancient Egypt Transformed: The Middle Kingdom (pp. 33-36). New York: Metropolitan Museum of Art.

"Yamamoto, K. (2015b). Abydos and Osiris. The Terrace of the Great God. En A. Oppenheim, D. Arnold y K. Yamamoto (Eds.), Ancient Egypt Transformed: The Middle Kingdom (pp. 250-269). New York: Metropolitan Museum of Art. 